\title{
11. Appropriateness of Colonoscopy: Inflammatory Bowel Disease ${ }^{1}$
}

\author{
F. Froehlich*, T. Larequi-Lauber**, J.-J. Gonvers*, R. W. Dubois***, B. Burnand**, J.-P. Vader** \\ * Policlinique Médicale Universitaire, Lausanne, Switzerland \\ ** Institut Universitaire de Médecine Sociale et Préventive, Lausanne, Switzerland \\ *** Protocare Sciences, Santa Monica, USA
}

\section{Introduction}

The use of colonoscopy to diagnose and follow up patients with inflammatory bowel disease is widely accepted. However, there is considerable uncertainty as to when colonoscopy is appropriate with respect to clinical symptoms, response to treatment and results of previous investigations. Uncertainty is even more important regarding the most appropriate use of colonoscopy in cancer screening in IBD.

In November 1998, a multidisciplinary European expert panel convened in Lausanne, Switzerland, to discuss and develop criteria for the appropriate use of gastrointestinal endoscopy, a widely-used procedure, regarded as highly accurate and safe. The RAND appropriateness method was chosen for this purpose, because it allows the development of appropriateness criteria based on published evidence and supplemented by explicit expert opinion. A detailed description of the RAND appropriateness method, including the literature search process [1], and of the whole process, as well as the global results of the panel [2], are published as separate articles in this issue of the Journal. The literature review was based on a systematic search of Medline, Embase and the Cochrane Library conducted up to the end of 1997 and completed with some key articles published in 1998. Updating and revision of the literature review is currently ongoing.

This article presents the literature review on IBD that was provided to the panelists for study and comment prior to the panel to support their ratings of appropriateness of colonoscopy in IBD. In addition, an overview of the main panel results related to IBD and a summary of published evidence and panel based appropriateness criteria are presented.

\section{Literature Review}

\section{Introduction}

We found few studies which assessed the impact of colonoscopy on patient outcome in inflammatory bowel disease. Guidelines developed in 1992 by the American Society for Gastrointestinal Endoscopy recommend diagnostic colonoscopy only if the result could favourably influence initial diagnosis and management, or for cancer surveillance.

\section{Initial Diagnosis and Management of Active Disease}

\section{Ulcerative Colitis}

Colonoscopic visualisation of mucosal appearance and the pattern of disease involvement in the colon in its entirety can confirm the diagnosis in $80-90 \%$ of cases [3], with a positive predictive value of more than $97 \%$ [4]. Total colonoscopy is particularly helpful when there is any doubt about the exact nature of the inflammatory bowel disease (i.e. Crohn's Disease, ulcerative colitis, microscopic colitis). Ulcerative colitis can usually be diagnosed by means of sigmoidoscopy [5], but in some rare cases, however, the disease is discontinuous with the rectum being spared [6].

Diagnosis by means of total colonoscopy is also helpful in documenting the extent of the disease, thus providing valuable prognostic information. Patients with diagnosed ulcerative pancolitis show a high proportion of colectomies for uncontrolled disease in the first three years after diagnosis $[7,8]$. Furthermore, the disease pattern is not static and may evolve over time, generally towards more severe disease: one-third of patients with proctitis and $70 \%$ of patients with left-sided only colitis at initial diagnosis showed

\footnotetext{
1 The European Panel on Appropriateness of Gastrointestinal Endoscopy (EPAGE, Lausanne, Switzerland)
} 
a progression to pancolitis after initial disease staging $[9$, 10]. Major changes in the extent of disease are usually detectable within the first ten years [10].

In most instances, disease activity can reliably be monitored using a combination of clinical signs and symptoms in conjunction with flexible sigmoidoscopy. The frequency and quantity of satisfactory bowel movements correlates with the degree of severity of the disease $[7,8]$. Colonoscopy permits evaluation of the extent of the disease in those cases where proctitis does not respond as expected to a course of topical therapy.

In expert hands, colonoscopy of acute colitis may be safe and may serve to select patients with high risk surgical complications who need early surgery in case of failure of medical treatment [11].

Signs of inflammation detected at endoscopy and the clinical symptoms are generally considered to show a strong correlation in ulcerative colitis. Procto-sigmoidoscopy thus correlated well with patient symptoms in a study evaluating the effectiveness of mesalamine as a long-term maintenance therapy [12]. Endoscopic signs of inflammation may, however, equally precede clinical symptoms in patients with as yet clinically inactive colitis [13]. We did not find evidence that titration of medication based on endoscopic findings resulted in better patient outcome. A well-designed prospective randomised clinical trial evaluated the effect on patient outcome when steroid dose reduction was correlated to either clinical or endoscopic remission [14]. One group of patients (clinical and endoscopic remission) commenced steroid reduction immediately, and a second group (clinical but not endoscopic remission) received five additional weeks of steroids prior to dose reduction. In this study, no differences were reported in remission rates, numbers of patients successfully weaned of steroids, or relapse rate after 18 months.

\section{Crohn's Disease}

When there is a strong clinical suspicion of Crohn's disease, colonoscopy up to the terminal ileum with ileal biopsies is valuable in confirming or excluding the illness [3, 4]. Small bowel radiography provides good diagnostic information in patients with ileal or ileocolic Crohn's disease. Up to $20 \%$ of patients will, however, show normal radiographic findings. Crohn's disease patients with ileocolic disease more frequently require operative treatment and develop more disease-related morbidity (fistulae, abscesses) than those with colitis only [15].

Disease activity is at present measured by clinical indices [12]. In Crohn's disease, clinical disease activity correlated poorly with mucosal lesions and biological activity [16]. In the evaluation of the effectiveness of drug therapy, the majority of authors recommend clinical indices $[17,18]$, while others favour endoscopy [19]. For patients who have reached clinical remission, adjustment of steroid treatment on the basis of colonoscopic findings does not result in added benefit, compared to the use of clinical symptoms alone [14].

\section{Initial Screening for Cancer in Patients with IBD}

\section{Ulcerative Colitis}

Epidemiology. Ulcerative colitis patients have a 20 -fold increase in risk of the development of colorectal cancer in comparison to age- and gender-matched control patients [20]. The extent and duration of disease at diagnosis are the major determinants of the magnitude of this increased risk: the relative risk is highest in patients with pancolitis (14.8), less for patients with left-sided colitis (2.8), and lowest for patients with proctitis (1.7) [21]. The absolute risk for developing colorectal cancer in patients with pancolitis is $5-10 \%$ after 20 years', $7-14 \%$ after 25 years' and $30-40 \%$ after 35 years' duration $[22,23]$. Age at onset of disease is an important variable for cancer risk both for left-sided colitis and pancolitis (SIR, standardised incidence ratios) [21] (Table 1).

Table 1 Colorectal cancer risk according to age at onset of disease and extension of colitis (adapted from Ebkom et al. 1990) [21]

\begin{tabular}{|c|c|c|}
\hline $\begin{array}{l}\text { Age at onset } \\
\text { of disease }\end{array}$ & Left-sided colitis & Pancolitis \\
\hline $15-29$ & $14.2(5.7-29.3)$ & $33.1(18.1-55.5)$ \\
\hline $30-39$ & $3.5(0.7-10.2)$ & $17.8(8.5-32.7)$ \\
\hline $40-49$ & $1.9(0.2-6.7)$ & $12.5(6.4-21.7)$ \\
\hline$\geq 50$ & $1.3(0.4-3.1)$ & - \\
\hline $50-59$ & - & $8.1 \quad(3.3-16.7)$ \\
\hline$\geq 60$ & - & $6.0(2.7-11.4)$ \\
\hline
\end{tabular}

Dysplasia. Dysplastic changes are considered to be predictive of colorectal cancer in ulcerative colitis patients. Multicentric tumours can occur in the area of chronic inflammation [24]. A recent review of ten prospective studies showed that $12 \%$ of patients with UC had cancer or dysplasia at the initial surveillance examination [22]. Lowgrade dysplasia is predictive of high-grade dysplasia or cancer. Long-term follow-up studies showed that the predictive value of low-grade dysplasia was $35 \%$ for highgrade dysplasia [25], and $54 \%$ for high-grade dysplasia or cancer [26]. There are, however, several problems related to the question of dysplasia: firstly, the diagnosis of lowgrade dysplasia is subject to gross inter-observer error [27]: inter-observer agreement on the grade of dysplasia is poor, ranging from 42 to $72 \%[28,29]$. Secondly, the proportion of cancers arising from a background of colitis and occurring without a detectable phase of dysplasia may be as high as $25 \%$ [30]-50\% [23,31-33] Thirdly, some studies have shown that low-grade dysplasia is not predictive of the development of colorectal cancer in the absence of a mass lesion $[22,33]$. 
Surveillance. Surveillance strategy is based on the assumption that dysplastic lesions can be detected before invasive cancer has developed [22]. Most of the data stem from studies investigating variations in sampling protocols and different clinical approaches in patients with indeterminate, low- and high-grade dysplasia in the context of surveillance programmes [31-34]. There is some lowstrength evidence that surveillance programmes do indeed improve patient outcome. A retrospective study [35] found that patients undergoing surveillance had cancer detected at an earlier stage than patients who were not followed up, resulting in a significant improvement in the five-year survival rate $(77 \%$ compared to $36 \%$ ). Colonoscopic surveillance for dysplasia in ulcerative colitis patients is recommended as an alternative to prophylactic colectomy, in particular in patients with total ulcerative colitis, and surveillance should begin seven to ten years after diagnosis $[32,36-39]$. The optimum interval between surveillance colonoscopies is not clear, but could most probably be in excess of one year when the first control colonoscopy is negative [22]. Multiple biopsies should be carried out during the same colonoscopy [24]. In conclusion, the literature data support surveillance, while at the same time recognising its limitations $[31,33,40-42]$.

Patient compliance is a major determinant which limits the effectiveness of surveillance programmes in ulcerative colitis patients $[25,26,31,32,34,42]$. The question of the cost-effectiveness of surveillance programmes is still being studied [31,32]. In a large prospective surveillance study in 160 patients with long-standing and extensive ulcerative colitis, representing a total of 739 colonoscopies (performed between 1978 and 1990) and 709 patient years of follow-up, only one out of a total of nine colitis-related cancers was detected by the surveillance programme, thus casting some doubt on its effectiveness [43]. In contrast, a retrospective review of 248 patients with extensive ulcerative colitis (mean duration of disease 12 years) detected seven patients with cancer, six of whom were identified at colonoscopy, and one patient with negative visual endoscopic findings was discovered by means of surveillance biopsies. It is too early to evaluate the benefit of alternative techniques such as DNA aneuploidy and biopsies [24, 36].

Crohn's disease. Patients with Crohn's disease have an estimated six-fold increase in risk of bowel cancer compared to the general population $[30,44]$. This relative risk is similar to the risk for patients with left-sided ulcerative colitis in a referral-based strategy [20]. When Crohn's patients with long-standing colitis or ileitis also show dysplastic changes [45 -47], the risk of carcinoma is particularly high in those loops of bowel bypassed at operation and in longstanding fistulae [47]; and the risk is higher in patients who were less than 30 years old at diagnosis (relative risk 20.9), compared to patients for whom the diagnosis of Crohn's disease was made at a later age (relative risk 2.2). Incidence of small bowel cancer is significantly increased in Crohn's disease (relative risk 86 in ileocolitis,
115 in regional enteritis) [20]. The average time from onset of Crohn's disease to diagnosis of carcinoma is about 16 years: these patients may therefore benefit from periodic screening beginning after this interval of time. However, for the time being, there is no unequivocal evidence that surveillance of patients with Crohn's disease results in improved outcome with respect to colorectal cancer.

\section{Panel Results}

The experts of the European panel on appropriateness of gastrointestinal endoscopy (EPAGE) considered the above literature review as well as their own clinical expertise in evaluating the appropriateness of colonoscopy for inflammatory bowel disease (IBD). Definitions of terms, clinical variables used, general and specific panel results related to IBD are presented.

\section{Definition of Terms}

Table 2 shows the definitions used by the European expert panel on gastrointestinal endoscopy to assess appropriateness of colonoscopy for IBD.

Table 2 Definitions used by the European expert panel on gastrointestinal endoscopy to assess appropriateness of colonoscopy for IBD

\section{Ulcerative colitis}

Documented by one or more of the following: endoscopic appearance, mucosal biopsy, operative report with pathology and infectious cause excluded.

\section{Crohn's disease}

Documented by one or more of the following: endoscopic appearance, mucosal biopsy, radiography, operative report with pathology and infectious cause excluded.

Extension of IBD

Evaluation of the extension of the disease (proctitis, pancolitis, left-sided colitis) with no previous colonoscopy done.

Lower Gl evaluation

Sigmoidoscopy or SBFT (small bowel follow-through) performed within the last 3 months and since symptoms began, recurred or worsened. Sigmoidoscopy: flexible tube $(60 \mathrm{~cm})$.

\section{Low-grade dysplasia}

Low degree of a combination of architectural and cytological alterations such as gross distortion, hyperchromasia, enlarged nuclei, large nucleoli, loss of cellular polarity confirmed within the basement membrane of the glands in which it arose.

High-grade dysplasia

High degree of a combination of architectural and cytological alterations such as gross distortion, hyperchromasia, enlarged nuclei, large nucleoli, loss of cellular polarity confirmed within the basement membrane of the glands in which it arose.

Therapy

Daily treatment for at least 14 days with one or more of the following: 5-ASA (enema, suppositories or oral), sulfasalazine, topical steroids or daily prednisone for at least 2 weeks or alternate day prednisone for at least 4 weeks or daily treatment with one of the following for at least 60 days: azathioprine, cyclosporine, 6-MP. 


\section{Clinical Variables}

The clinical variables and their levels of detail that were used to create and rate patient scenarios to assess the appropriateness of use of colonoscopy in patients with known IBD are listed in Table $\mathbf{3} \mathbf{a}$ and in Table $\mathbf{3} \mathbf{b}$ for cancer screening in IBD.

Table 3a Clinical variables used in inflammatory bowel disease (UC: ulcerative colitis, CD: Crohn's disease)

\begin{tabular}{|c|c|c|}
\hline Variables & $\begin{array}{l}\text { Number of } \\
\text { categories }\end{array}$ & Categories \\
\hline IBD & 3 & $\begin{array}{l}\text { - known UC } \\
\text { - known CD without colitis } \\
\text { - known CD with colitis }\end{array}$ \\
\hline Therapy & 2 & $\begin{array}{l}\text { - no therapy } \\
\text { - current therapy }\end{array}$ \\
\hline Symptoms & 2 & $\begin{array}{l}\text { - symptoms absent or } \\
\text { improved } \\
\text { - symptoms unimproved } \\
\text { or worse }\end{array}$ \\
\hline $\begin{array}{l}\text { Evaluation of the ex- } \\
\text { tension of IBD no } \\
\text { previous colonoscopy }\end{array}$ & 2 & $\begin{array}{l}\text { - evaluation of CD } \\
\text { - evaluation of UC }\end{array}$ \\
\hline \multicolumn{3}{|l|}{ Evaluation done } \\
\hline - for UC & 3 & $\begin{array}{l}\text { - no recent sigmoidoscopy } \\
\text { - normal sigmoidoscopy } \\
\text { - active disease at sigmo- } \\
\text { idoscopy }\end{array}$ \\
\hline - for UD & 3 & $\begin{array}{l}\text { - no recent SBFT } \\
\text { - normal SBFT } \\
\text { - active disease at SBFT }\end{array}$ \\
\hline
\end{tabular}

Table $\mathbf{3} \mathbf{b}$ Clinical variables for cancer screening in patients with known IBD

\begin{tabular}{|c|c|c|}
\hline Variables & $\begin{array}{l}\text { Number of } \\
\text { categories }\end{array}$ & Categories \\
\hline \multicolumn{3}{|l|}{$\begin{array}{l}\text { Data of last screening } \\
\text { colonoscopy }\end{array}$} \\
\hline - for UC & 3 & $\begin{array}{l}- \text { no index colonoscopy } \\
-\leq 2 \text { years ago } \\
->2 \text { years ago }\end{array}$ \\
\hline - for $C D$ & 3 & $\begin{array}{l}\text { - no index colonoscopy } \\
-\leq 3 \text { years ago } \\
->3 \text { years ago }\end{array}$ \\
\hline \multicolumn{3}{|l|}{ Extension of IBD* } \\
\hline - for UC & 3 & $\begin{array}{l}\text { - UC proctitis } \\
\text { - UC left-sided colitis } \\
\text { - UC pancolitis }\end{array}$ \\
\hline- for $C D$ & 2 & $\begin{array}{l}\text { - without colitis } \\
\text { - with colitis }\end{array}$ \\
\hline Result of last biopsy & 2 & $\begin{array}{l}\text { - dysplasia never detected } \\
\text { - low-grade dysplasia }\end{array}$ \\
\hline $\begin{array}{l}\text { Time since disease } \\
\text { onset }\end{array}$ & 3 & $\begin{array}{l}-<8 \text { years } \\
-8-15 \text { years } \\
->15 \text { years }\end{array}$ \\
\hline
\end{tabular}

* diagnosis at last colonoscopy

\section{General Panel Results}

IBD was assessed in 59 clinical scenarios stratified into 4 categories : Evaluation of known UC (13 items), evaluation of known CD (17 items), screening for colorectal cancer in patients with known UC (19 items) and screening for colorectal cancer in patients with known CD (10 items). Of the 59 scenarios, $24(41 \%)$ were rated appropriate, $10(17 \%)$ uncertain and $25(42 \%)$ inappropriate. The rate of overall agreement of panelists for these scenarios was $56 \%$.

\section{Specific Clinical Panel Results}

The main results for the appropriateness of colonoscopy in IBD are worded as overall statements representing several clinical scenarios. In some cases, because of the matrixlike nature of scenario development, the same scenario may be included in more than one statement. Forty-two of the 59 indications $(71 \%)$ could be characterized by the 11 overall statements in Tables $\mathbf{4 a}$ and $\mathbf{4 b}$. Detailed appropriateness and necessity criteria on the appropriate or crucial nature of colonoscopy, including voting distributions of panelists, are available in a computerized form, accessible via Internet at the EPAGE web site (http://www.epage.ch).

\section{Description of Appropriateness}

Appropriateness of use of colonoscopy is described in Table $\mathbf{3} \mathbf{a}$ for known IBD and in Table $\mathbf{4} \mathbf{b}$ for cancer screening in IBD.

\section{Description of Necessity}

Ten out of 59 scenarios $(17 \%)$ related to IBD were judged necessary. Necessary indications are summarized by 3 statements in Table $\mathbf{5}$ and pertained exclusively to cancer screening in IBD patients. In some cases, the same scenario may apply to more than one statement.

\section{Conclusions}

Colonoscopy reliably assesses the type, extension and evolution of inflammatory bowel disease (IBD). In Crohn's disease, small bowel disease may be evaluated by a small bowel follow-through (SBFT). Risk of colorectal cancer increases with extent and duration of the disease, particularly in UC. Though the importance of dysplasia as a precancerous lesion is recognized, there is only very limited evidence that surveillance programmes do indeed improve patient outcome. In addition, the optimum interval in which screening colonoscopy has to be performed remains unclear.

In IBD, $42 \%$ of the clinical scenarios were judged to be inappropriate indications for colonoscopy. Seventeen percent of clinical scenarios were judged necessary, all of which dealt with colorectal cancer screening in IBD patients. Seventy-eight percent of the scenarios could be encompassed in 12 descriptive clinical statements. The de- 
Table 4a Description of appropriateness of indications for colonoscopy for known IBD

\section{Clinical situations}

In individuals with known ulcerative colitis of Crohn's disease with no previous colonoscopy, indication for colonoscopy is appropriate to evaluate the extension of disease

In individuals with known ulcerative colitis of Crohn's disease with improved or no symptorns, with or without current therapy, indication for colonoscopy is inappropriate

In individuals with known ulcerative colitis with unimproved or worsened symptoms without current therapy, indication for colonoscopy is generally appropriate

In individuals with known Crohn's disease with unimproved or worsened symptoms, with or without current therapy, and normal SBFT, indication for colonoscopy is generally appropriate

In individuals with known Crohn's disease with unimproved or worsened symptoms without current therapy, indication for colonoscopy is generally uncertain

In individuals with known Crohn's disease with unimproved or worsened symptoms without therapy, indication for colonoscopy is

generally inappropriate

Table $\mathbf{4} \mathbf{b}$ Description of appropriateness of indications for colonoscopy for cancer screening in IBD

\section{Clinical situations}

In individuals with known ulcerative colitis, indication for colonoscopy is

generally appropriate if an index endoscopy has never been done

In individuals with known ulcerative colitis who had a colonoscopy

2 years or less previously, indication for colonoscopy is generally inappropriate

In individuals with known ulcerative colitis or Crohn's disease for $>15$ years, indication for colonoscopy is

appropriate if interval since last screening endoscopy is:

ulcerative colitis $>2$ years

Crohn's disease $>3$ years

In individuals with known ulcerative colitis or Crohn's disease with low-grade dysplasia, indication for colonoscopy is appropriate

In individuals with known ulcerative colitis limited to proctitis or with Crohn's disease without colonic involvement, indication for colonoscopy is

inappropriate

tailed and specific character of these criteria are best revealed in the computerized form available on the Internet (http://www.epage.ch).

\section{Acknowledgement}

The authors gratefully acknowledge the selfless commitment and invaluable contribution of the expert panel members, who made this project possible: Marcello Anti (IT),
Table 5 Description of necessary indications for colonoscopy for screening for colorectal cancer in patients with known ulcerative colitis or Crohn's disease

\section{Clinical situations}

In individuals with known ulcerative colitis with low-grade dysplasia, indication for colonoscopy is

necessary unless last colonoscopy has been done less than

3 years previously in patients with Crohn's disease

In individuals with known ulcerative colitis or Crohn's disease and no index colonoscopy, indication for colonoscopy is

necessary if interval since disease onset is:

pancolitis: $\geq 8$ years left-sided colitis or

Crohn's disease: $>15$ years

In individuals with known ulcerative colitis for $>15$ years, indication for colonoscopy is

necessary if last the colonoscopy has been performed $>2$ years previously

Peter Bytzer (DK), Mark Cottrill (UK), Michael Fried (CH), Roar Johnsen (NO), Gerd Kanzler (DE), François Lacaine (FR), Cornelis Lamers (NL), Roger J. Leicester (UK), Mattijs E. Numans (NL), Javier P. Piqueras (SP), Jean-François Rey (FR), Giacomo Sturniolo (IT), Robert P. Walt (UK). This work was supported by the EU BIOMED II Programme (BMH4-CT96-1202), the Swiss National Science Foundation (32.40522.94) and the Swiss Federal Office of Education and Science (95.0306-2).

\section{References}

' Vader JP, Burnand B, Froehlich F, Dubois RW, Bochud M, Gonvers JJ. The European Panel on Appropriateness of Gastrointestinal Endoscopy (EPAGE): Project and methods. Endoscopy 1999; 31: $572-578$

${ }^{2}$ Vader JP, Froehlich F, Dubois RW, Beglinger C, Wietlisbach V, Pittet V, Ebel N, Gonvers JJ, Burnand B. The European Panel on the Appropriateness of Gastrointestinal Endoscopy (EPAGE): Conclusions and WWW site. Endoscopy 1999; 31: 687-694

${ }^{3}$ Rutgeerts P, Vantrappen G, Geboes K. Endoscopy in inflammatory bowel disease. Scand J Gastroenterol Suppl 1989; 170: $12-15$

${ }^{4}$ Mantzaris GJ, Hatzis A, Archavlis E, Petraki K, Lazou A, Triantafyllou G, Raptis SA. The role of colonoscopy in the differential diagnosis of acute, severe hemorrhagic colitis. Endoscopy 1995; 27: 645-653

${ }^{5}$ Schumacher G, Sandstedt B, Kollberg B. A prospective study of first attacks of inflammatory bowel disease and infectious colitis-Clinical findings and early diagnosis. Scand J Gastroenterol 1994; 29: 265-274

${ }^{6}$ Geboes K, Delabie J, Rutgeerts P, Vantrappen G. Endoscopy as a diagnostic tool in inflammatory bowel disease. Acta Chirurgica Belgica 1989; 89: 106-110

${ }^{7}$ Podolsky DK. Inflammatory bowel disease (1). N Engl J Med 1991; 325: 928-937

${ }^{8}$ Podolsky DK. Inflammatory bowel disease (2) (see comments). N Engl J Med 1991; 325: 1008-1016

${ }^{9}$ Farmer RG, Easley KA, Rankin GB. Clinical patterns, natural history, and progression of ulcerative colitis. A long-term follow-up of 1116 patients. Dig Dis Sci 1993; 38: 1137-1146 
${ }^{10}$ Langholz E, Munkholm P, Davidsen M, Nielsen OH, Binder V. Changes in extent of ulcerative colitis: a study on the course and prognostic factors. Scand J Gastroenterol 1996; $31: 260-$ 266

${ }^{11}$ Carbonnel F, Lavergne A, Lemann M, Bitoun A, Valleur P, Hautefeuille P, Galian A, Modgliani R, Rambaud JC. Colonoscopy of acute colitis. A safe and reliable tool for assessment of severity. Digestive Diseases \& Sciences 1994; 39: 1550-1557

${ }^{12}$ Hanauer SB, Sninksy CA, Robinson M, Powers BY, McHattie JD, Mayle JE, Elson CO, DeMicco MP, Butt JH, Pruitt RE, et al. An oral preparation of mesalamine as long-term maintenance therapy for ulcerative colitis. A randomized, placebocontrolled trial. Ann Intern Med 1996; 124: 204-211

${ }^{13}$ Courtney MG, Nunes DP, Bergin CF, O'Driscoll M, Trimble V, Keeling PW, Weir DG. Randomised comparison of olsalazine and mesalazine in prevention of relapses in ulcerative colitis. Lancet 1992; 339: 1279-1281

${ }^{14}$ Landi B, Anh TN, Cortot A, Soule JC, Rene E, Gendre JP, Bories P, See A, Metman EH, Florent C, et al. Endoscopic monitoring of Crohn's disease treatment: a prospective, randomized clinical trial: The Groupe d'Etudes Therapeutiques des Affections Inflammatoires Digestives. Gastroenterology 1992; 102: 1647-1653

${ }^{15}$ Farmer RG, Whelan G, Fazio VW. Long-term follow-up of patients with Crohn's disease. Relationship between the clinical pattern and prognosis. Gastroenterology 1985; 88: 1818-1825

${ }^{16}$ Bo-Linn GW, Vendrell DD, Lee E, Fordtran JS. An evaluation of the significance of microscopic colitis in patients with chronic diarrhea. Journal of Clinical Investigation 1985; 75: $1559-1569$

${ }^{17}$ Rutgeerts P, Lofberg R, Malchow $H$, Lamers C, Olaison $G$, Jewell D, Danielsson A, Goebell H, Thomsen OO, Lorenz-Meyer $\mathrm{H}$, et al. A comparison of budesonide with prednisolone for active Crohn's disease. N Engl J Med 1994; 331: 842-845

${ }^{18}$ Greenberg GR, Feagan BG, Martin F, Sutherland LR, Thomson $A B$, Williams CN, Nilsson LG, Persson T. Oral budesonide for active Crohn's disease. Canadian inflammatory bowel disease study group. N Engl J Med 1994; 331: 836-841

${ }^{19}$ Vasen HF, Taal BG, Nagengast FM, Griffioen G, Menko FH, Kleibeuker JH, Offerhaus GJ, Meera Khan P. Hereditary nonpolyposis colorectal cancer: results of long-term surveillance in 50 families. Eur J Cancer 1995; 31: 1145-1148

${ }^{20}$ Greenstein AJ, Sachar DB, Smith H, Janowitz HD, Aufses AH Jr. A comparison of cancer risk in Crohn's disease and ulcerative colitis. Cancer 1981; 48: 2742-2745

${ }^{21}$ Ekbom A, Helmick C, Zack M, Adami HO. Ulcerative colitis and colorectal cancer. A population-based study. N Engl J Med 1990; 323: 1228-1233

${ }^{22}$ Bernstein CN, Shanahan F, Weinstein WM. Are we telling patients the truth about surveillance colonoscopy in ulcerative colitis? Lancet $1994 ; 343: 71-74$

${ }^{23}$ Ransohoff DF. Colon cancer in ulcerative colitis. Gastroenterology 1988; 94: 1089-1091

${ }^{24}$ Jain SK, Peppercorn MA. Inflammatory bowel disease and colon cancer-a review. Digestive Diseases 1997; 15: 243-252

${ }^{25}$ Lindberg B, Persson B, Veress B, Ingelman-Sundberg $\mathrm{H}$, Granqvist S. Twenty years' colonoscopic surveillance of patients with ulcerative colitis. Detection of dysplastic and malignant transformation. Scan J Gastroenterol 1996; 31: 11951204

${ }^{26}$ Connell WR, Lennard-Jones IE, Williams CB, Talbot IC, Price $\mathrm{AB}$, Wilkinson $\mathrm{KH}$. Factors affecting the outcome of endoscopic surveillance for cancer in ulcerative colitis (see comments). Gastroenterology 1994; 107: 934-944
${ }^{27}$ Dyck WP, Cloud ML, Offen WW, Matsumoto C, Chemish SM. Treatment of duodenal ulceration in the United States. Scand J Gastroenterol Suppl 1987; 136: 47-55

${ }^{28}$ Melville DM, Jass JR, Morson BC, Pollock DJ, Richman PI, Shepherd NA, Ritchie JK, Love SB, Lennard-Jones JE. Observer study of the grading of dysplasia in ulcerative colitis: comparison with clinical outcome. Hum Pathol 1989; 20: 10081014

${ }^{29}$ Dixon MF, Brown LJ, Gilmour HM, Price AB, Smeeton NC, Talbot IC, Williams GT. Observer variation in the assessment of dysplasia in ulcerative colitis. Histopathology 1988; 13: $385-397$

${ }^{30}$ Korelitz BI. Considerations of surveillance, dysplasia, and carcinoma of the colon in the management of ulcerative colitis and Crohn's disease. Med Clin North Am 1990; 74: 189-199

${ }^{31}$ Lennard-Jones JE. Is colonoscopic cancer surveillance in ulcerative colitis essential for every patient? Eur J Cancer 1995; 31: $1178-1182$

${ }^{32}$ Collins RH Jr, Feldman M, Fordtran JS. Colon cancer, dysplasia, and surveillance in patients with ulcerative colitis. A critical review. N Engl J Med 1987; 316: 1654-1658

${ }^{33}$ Axon AT. Colonic cancer surveillance in ulcerative colitis is not essential for every patient? Eur J Cancer 1995; 31: 1183-1186

${ }^{34}$ Lennard-Jones JE. Cancer risk in ulcerative colitis: surveillance or surgery. Br J Surg 1985; 72: S84-S86

${ }^{35}$ Choi PM, Nugent FW, Schoetz DJ Jr, Silverman ML, Haggitt RC. Colonoscopic surveillance reduces mortality from colorectal cancer in ulcerative colitis. Gastroenterology 1993; 105 : $418-424$

${ }^{36}$ Lofberg R, Brostrom O, Karlen P, Tribukait B, Ost A. Colonoscopic surveillance in long-standing total ulcerative colitis-a 15-year follow-up study. Gastroenterology 1990; 99: 10211031

${ }^{37}$ Lashner BA. Recommendations for colorectal cancer screening in ulcerative colitis: a review of research from a single university-based surveillance program. Am J Gastroenterol 1992; 87: $168-175$

${ }^{38}$ Fuson JA, Farmer RG, Hawk A, Sullivan BH. Endoscopic surveillance for cancer in chronic ulcerative colitis. Am J Gastroenterol 1980; 73: 120-126

${ }^{39}$ Matiushichev VB, Soldatov AI. High energy laser irradiation in the combined treatment of duodenal ulcer. Klin Med Mosk $1994 ; 72 ; 15-16$

${ }^{40}$ Martin LF. Stress ulcers are common after aortic surgery. Endoscopic evaluation of prophylactic therapy. American Surgeon 1994; 60: $169-174$

${ }^{41}$ Rozen P, Baratz M, Fefer F, Gilat T. Low incidence of significant dyplasia in a successful endoscopic surveillance program of patients with ulcerative colitis (see comments). Gastroenterology 1995; 108: $1361-1370$

42 Jonsson B, Ahsgren L, Andersson LO, Stenling R, Rutegard J. Colorectal cancer surveillance in patients with ulcerative colitis. British Journal of Surgery 1994; 81: 689-691

${ }^{43}$ Lynch DA, Lobo AJ, Sobala GM, Dixon MF, Axon AT. Failure of colonoscopic surveillance in ulcerative colitis. Gut 1993; 34: $1075-1080$

${ }^{44}$ Ekbom A, Helmick C, Zack M, Adami HO. Increased risk of large-bowel cancer in Crohn's disease with colonic involvement. Lancet 1990; 336:357-359

${ }^{45}$ Richards ME, Rickert RR, Nance FC. Crohn's disease-associated carcinoma. A poorly recognized complication of inflammatory bowel disease. Annals of Surgery 1989; 209: 764-773 
${ }^{46}$ Craft CF, Mendelsohn G, Cooper HS, Yardley JH. Colonic "precancer" in Crohn's disease. Gastroenterology 1981; 80: 578-584

${ }^{47}$ Hamilton SR. Colorectal carcinoma in patients with Crohn's disease. Gastroenterology 1985; 89: 398-407
Corresponding Author

Florian Froehlich, MD, PD

Senior Lecturer in Gastroenterology Policlinique Médicale Universitaire

Rue César-Roux 19

CH-1005 Lausanne

Switzerland

Fax: $\quad+41-32-4662955$

E-mail: florian.froehlich@bluewin.ch 